\title{
Systolic time intervals: a review of the method in the non-invasive investigation of cardiac function in health, disease and clinical pharmacology
}

\author{
S. HASSAN \\ M.B., Ch.B. \\ P. TURNER \\ B.Sc., M.D., F.R.C.P. \\ Department of Clinical Pharmacology, St Bartholomew's Hospital, London ECIA 7BE
}

\begin{abstract}
Summary
Measurement of systolic time intervals is a valuable, non-invasive procedure to assess left ventricular performance, particularly when influenced by drugs. In this review, we discuss various factors affecting systolic time intervals, the therapeutic implications of the technique and its place among other non-invasive tests of cardiac function.
\end{abstract}

KEY WORDS: non-invasive techniques, systolic time intervals, echocardiography, clinical pharmacology.

\section{Introduction}

Despite the early introduction of simultaneous recording of the heart sounds, the central arterial pulse tracing and the electrocardiogram (ECG) to define the intervals in the cardiac cycle, their clinical application as an investigative tool received little attention until the early 1960's (Weissler, Peeler and Roehll, 1961). This delay can be attributed to the fact that the physiological implications of the systolic time interval (STI) could not be validated until comparisons with direct measures of cardiac function such as cardiac catheterization and ventriculography became clinically available, and thus the importance of these measurements was appreciated (Weissler, 1977). The determination of STI offers a convenient, non-invasive method to study changes in left ventricular performance (Weissler, Harris and Schoenfeld, 1969) and the effects of therapeutic interventions or diseases on myocardial performance.

Definitions and measurement of systolic time intervals (STI)

The STI (Weissler et al., 1961; 1969; Weissler, 1977) represent the duration of total electro-mechanical systole with its two major components, the preejection and the ejection phases (Fig. 1). The total electro-mechanical systole (QS2) is the interval that spans the entire period of systole from the onset of the QRS complex on the ECG to the closure of the aortic valve as reflected by the first high frequency vibrations of the aortic component of the second heart sound. The left ventricular ejection time (LVET) is the phase of systole during which blood is ejected into the arterial system, and is measured from the beginning of the upstroke to the trough of the incisural notch on the external carotid arterial pulse tracing. The pre-ejection period (PEP) is the interval from the onset of ventricular depolarization to the beginning of the left ventricular ejection. It is derived by subtracting the LVET from the QS2. The calculation of PEP in this way discounts the time of delay due to transmission of the arterial pulse wave from the proximal aorta to the point of its detection over the external carotid artery (usually about $20 \mathrm{msec}$ ). Further attempts to subdivide the PEP into electromechanical delay and isovolumic contraction time have proved unsatisfactory. However, in patients with abnormalities of intra-ventricular conduction, determination of the electro-mechanical delay may be of value in the analysis of the duration of the PEP (Weissler, 1977). A simple informative way of presenting the STI can be provided by the use of PEP/LVET ratio (Weissler, 1977).

The STI are measured from simultaneous recording of an electrocardiogram, phonocardiogram and external carotid arterial pulse tracing using a multichannel photographic recording system. High quality equipment is essential. An ECG lead most clearly demonstrating the onset of ventricular depolarization wave (Q-wave) departing acutely from a flat baseline is required (usually lead II or a precordial lead). The phonocardiogram is recorded from the upper part of the precordium in a position optimal for recording the initial high frequency vibrations of the second heart sound (usually second left intercostal space). 


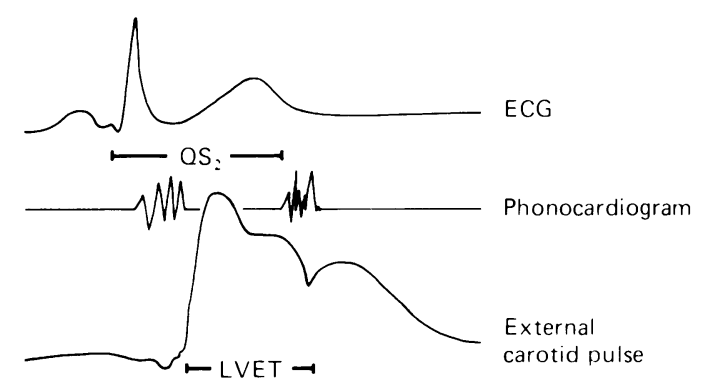

FIG. 1. Simultaneous recording of ECG, phonocardiogram and external carotid pulse tracings showing systolic time intervals $\mathrm{QS}_{2}=$ total electromechanical systole; $\mathrm{LVET}=$ left ventricular ejection time: $P E P=Q S_{2}-$ LVET

The microphone used should be in a range of frequency of $100-500 \mathrm{~Hz}$. The external carotid arterial pulse tracing is recorded with a high fidelity strain-gauge transducer that permitts a flat frequency response between $0 \cdot 1$ and $30 \mathrm{~Hz}$ and at least a $2 \cdot 0 \mathrm{sec}$ time constant. The transducer is placed firmly over the artery just below the carotid sinus. The arterial pulse tracing must show clearly the upstroke, which is the first thinning of the pulse line above the initial upward displacement of the isovolumic contraction, and a sharp single incisura. Before obtaining a permanent recording, it is advisable to scan an oscilloscopic display of the recordings to ascertain that each of the events from which the calculations are made is sharply inscribed. Ten successive beats are usually registered so as to allow for the effect of respiration (Lewis et al., 1977).

To obtain the best information from this technique, efforts are required to standardize its various technical proceedures including those of recording and of measurement. It should be performed at the same time of the day after 5 min rest (Lewis, 1975). Repeated recordings of the STI are preferably done on the same carotid artery for each subject, although no statistically significant difference was found between recordings done on both sides (Van De Werf $e t$ al., 1975). For accurate measurement of the STI, a paper speed of $100 \mathrm{~mm} / \mathrm{sec}$ is required (Weissler et al., 1969). This speed showed the smallest numerical differences in the measurement of STI when compared to other speeds (Spodick, Ball and Pigott, 1978). Calculation of the STI is considered as the mean of the 10 successive intervals. This has to be analysed carefully and without knowing the treatment taken, as changes of 10-30 msec may be the sole finding (Lewis et al., 1976; Kelman, Sumner and Whiting, 1981a). The measurements can either be done manually or with the aid of a programmed computerized digitizer which is quicker (Weerasuriya, 1982). Heart rate is calculated from the $R-R$ interval of the 10 heart beats.
Effect of heart rate on STI and derivation of the regression equations

It has long been appreciated that the systolsc phases of the cardiac cycle vary inversely with heart rate (Lewis et al., 1977). Thus, for deviations of S to be properly interpreted, corrections must be ma\&e for variations related to differences in heart rats (Lewis et al., 1977). Regression equations relatim each of the STI to the heart rate have been derives for clinical use in different age groups. The equations were used to derive the STI indices. Eagogh in fact, represents the measured interval extrapolated to zero heart rate, thus eliminating heart rate as. significant variable affecting the intervals (Weisslet Lewis and Leighton, 1972). The index is calculated the sum of the measured interval plus the product $\&$ f heart rate multiplied by slope of the regression equation. When compared to the normal index of the population, the calculated value gives a quantitatioe measure of the degree of deviation from normal ard offers a convenient expression to study serial changes during drug therapy. Unfortunately, there is if universal agreement about the currently available regression equations (Burgess, Wadsworth and Wartrington, 1979) and the best way by which they shoufer be derived. The most widely applied regression equations in practice are those derived by Weisslem Harris and Schoenfeld (1968) from STI recordeg on normal subjects with a wide range of resting hear rate. Recently, it has been suggested (Johnson e e $a \frac{9}{5}$, 1981) that they considerably over-correct for heaft rate changes and consequently will correct for totol effects of altered adrenergic stimulation rather than other factors affecting myocardial contractilit These slopes were similar to those obtained after infusion of isoprenaline (Johnson et al., 1981). ln addition, nearly all authors agree that PEP 贲 virtually independent of heart rate (Spodick, 1979: Burgess et al., 1979). Many investigators have used either atrial pacing (Johnson et al., 1981) or incrę: mental doses of atropine intravenously (Burgess $\underline{\theta} t$ al., 1979) to produce a range of heart rates and derine the regression equations. Kelman and associates $(1981 \mathrm{a}, \mathrm{b})$ believe that each subject must have his own equations when the inotropic effect of drugs being assessed by STI.

Each age group has its own regression equation derived from studying normal healthy subjects of both sexes resting supine (Table 1).

\section{Physiological variations of systolic time intervals Effect of age and sex}

Comparison of children, adolescents and adu店 shows a distinct tendency towards lengthening of afl the STI with increasing age, independent of change in heart rate (Wanderman et al., 1981). Compareg 
TABI.E I. Various regression equations

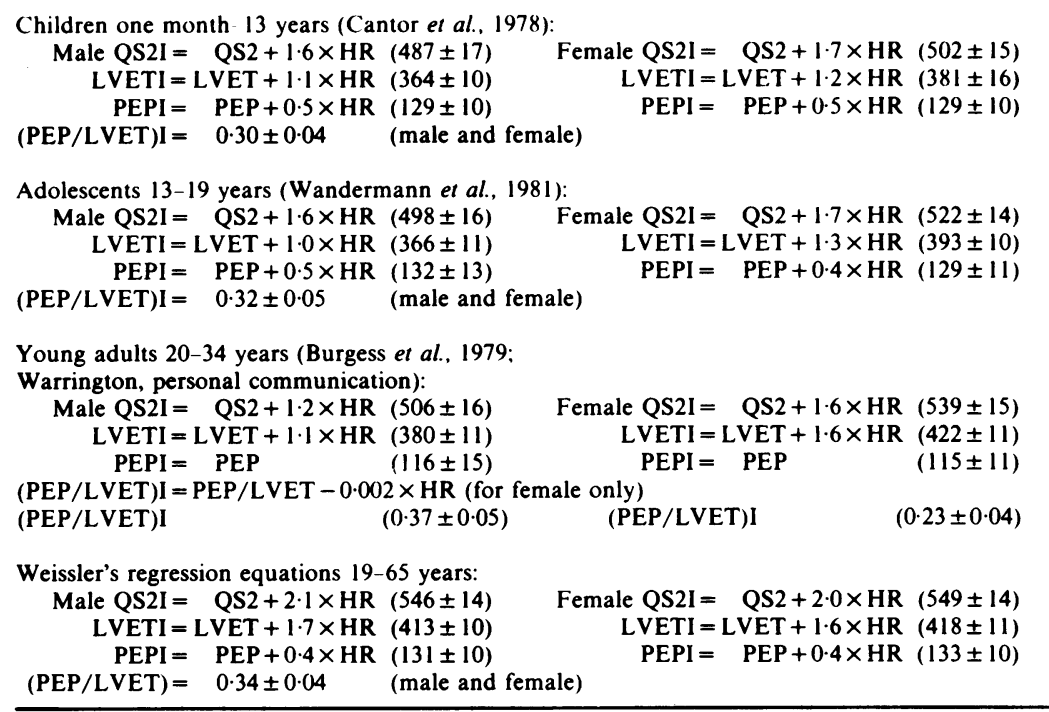

with the normal standards established by Weissler for adults, QS2 and PEP were shorter in children at all heart rates and LVET was shorter at heart rate up to 85 beats per min in males and 105 beats per min in females (Cantor et al., 1978). In adolescents, all STI are longer than those of children at all heart rates. When compared with adult values, PEP at all heart rates are shorter in adolescents while QS2 and LVET are shorter at the low or normal heart rates (Wanderman et al., 1981). The PEP lengthens proportionally more than the LVET, resulting in a progressively higher PEP/LVET ratio with development, from childhood $(0.30)$ to adolescent $(0.32)$ to adulthood (0.34) (Wanderman et al., 1981). In adults, a slight increase in PEP occurs with advancing age (Harrison et al., 1964). The tendency of lengthening of STI seems to continue in the elderly who have longer LVET (Willems et al., 1970) and QS2 (Slodki, Hussain and Luisada, 1969). No significant difference in STI between sexes was found in children (Golde and Burstin, 1970; Cantor et al., 1978) and in adolescents (Wanderman et al., 1981). In the adult, the differences in the regression equations for the sexes were significant for QS2 and LVET, but not for PEP (Weissler et al., 1969).

\section{Diurnal variation}

A diurnal decrease in LVET and QS2 unaccompanied by a significant change in PEP occurs in normal subjects (Weissler et al., 1965). This effect appears to reach its maximum between $4 \mathrm{pm}$ and $8 \mathrm{pm}$ and averages 8 and $10 \mathrm{msec}$ for LVET and QS2 respec- tively. It is for this reason that, as a standard procedure, the measurements should be made at the same time of the day preferably between 8 am and 10 am (Weissler et al., 1972).

\section{Day-to-day variation}

It is important to appreciate the day-to-day variation in STI, both in normal subjects and in patients (Lewis et al., 1977). This has been investigated by doing serial measurements of STI in both groups (Lewis, 1975). The mean one standard deviations of STI for individuals were smaller than the standard deviation values for the entire group. This indicates the consistency of STI, especially in normal subjects. The observed degree of day-to-day variation probably reflects variation in the degree of sympathetic drive to the heart (Johnson et al., 1981). Burgess and associates (1979) found that variation in the measured STI due to the investigator, analyser, time and photocopying process is very small in comparison with the variability of the subjects being studied, with the possible exception of PEP where the analyser was responsible for about $14 \%$ of the observed variability.

\section{Food}

The STI should be performed in the post-absorptive state, as food intake has a positive inotropic effect (reduction in QS2I, PEP and PEP/LVET ratio) and chronotropic effect (Burgess, 1981). LVETI showed no significant change. 


\section{Pregnancy}

Alterations in STI were found to occur during uncomplicated pregnancy (Rubler, Schneebaum and Hammer, 1973; Burg, Dodeck and Kloster, 1972; Kher, Grover and Durairaj, 1980). In the first and second trimesters, PEP was shortened and LVET prolonged, thereby significantly shortening PEP/ LVET ratio. In the third trimester, the reverse was found, that is prolongation of PEP, reduction in LVETI and an increase in PEP/LVET ratio. The findings in the first and second trimesters may suggest improved myocardial contractility. This improvement could be due to increased preload and ventricular diastolic filling resulting from the physiological increase in blood volume and also possibly due to hormonal influences. Decreased venous return and stroke volume by pressure of the gravid uterus on the inferior vena cava may be the explanation for the changes encountered in the third trimester in the supine position.

\section{Validation of systolic time intervals}

Validation of the STI has been a 2-stage process: first to establish the accuracy of external measurements, and second to correlate the STI with other, invasively obtained parameters of left ventricular function (Lewis et al., 1977). Several investigations in man have established the validity of the STI as a true representation of the corresponding intervals, both in the steady state and during acute interventions. LVET derived externally from carotid arterial pulse tracing was compared with recordings obtained simultaneously from fluid-filled catheters in the proximal aorta (Weissler et al., 1961; Robinson, 1963) and catheter-tip micromanometers in the central aorta (Bush et al., 1970; Martin et al., 1971; Van de Werf et al., 1975). While external LVET is delayed in time, it was shown to be an accurate reflection of internally measured LVET and changes produced by acute interventions (Martin et al., 1971) were identical when measured externally or internally. The external carotid arterial pulse tracing was almost identical to the intracarotid arterial pulse tracing (Van de Werf et al., 1975). At resting heart rates, externally measured PEP was found to correlate closely with internally measured PEP (Bush et al., 1970; Van de Werf et al., 1975) and with true isovolumic contraction time (IVCT) (Martin et al., 1971). Changes in PEP during acute interventions were identical to changes in true IVCT, thus validating the externally measured interval (Martin et al., 1971). The narrow range of normal for QS2 at all heart rates and pressure supports its reliability as a useful measure of the duration of systole (Lewis et al., 1977). The QS2 as measured externally ends with the first high frequency vibrations of the aortic compo- nent of the second heart sound. The externally and internally recorded A2 corresponds exactly with the nadir of the central aorta pulse tracing incisura 角 studied by catheter-tip micromanometer (Bush et af., 1970; Martin et al., 1971). The delay between A2 to the nadir of the incisura of the external carotid arterial pulse tracing measures $10-35 \mathrm{msec}$ at resting heart rates (Martin et al., 1971; Van de Werf et a a , 1975).

In the second stage of the validation of the ST, correlations were performed between various Sh. and parameters of $L V$ performance measured invEsively. A good and significant correlation was found between PEP/LVET ratio and left ventricular ejec tion fraction determined angiographically amorig patients with a wide variety of cardiovascular dis eases (Lewis et al., 1976; Weissler, Stack and Sohमु, 1980; Stack, Sohn and Weissler, 1981; Garragु; Weissler and Dodge, 1970; Ahmed et al., 1972). If patients with coronary artery disease, the PEP/LVES ratio affords a highly reproducible measure of $L$ global performance that is equivalent in accuracy the determination of $\mathrm{LV}$ ejection fraction (Stack $\boldsymbol{e}$ al., 1981; Weissler et al., 1980). Both PEP and LVEI correlated significantly with the ejection fraction in patients with a wide variety of cardiovascular di eases (Garrad et al., 1970). An inverse relationship between changes in left ventricular $\mathrm{dp} / \mathrm{dt}$ and BEE was found in dogs (Metzger et al., 1970) and in man (Martin et al., 1971). In subjects with either no LV or cardiac disease confined to the LV, PEP an PEP/LVET ratio exhibited excellent correlation wi measures of contractility (contractile element velocig at peak $\mathrm{dp} / \mathrm{dt}$, and the Frank-Levinson contractiling index) (Ahmed et al., 1972).

\section{Factors affecting systolic time intervals}

The STI are dependent on four determinants; hea rate, preload, afterload, and myocardial inotrope state (Table 2).

\section{PEP}

Almost all authors agree that PEP is independen of heart rate. Increases in heart rate with atrial pacing or with vagal withdrawal by atropine do not chang its value (Harris, Schoenfeld and Weissler, 1967 PEP varies inversely with stroke volume (Harle Starmer and Greenfield, 1969; Weissler et al., 1969) Reduction in preload and LV volume, as occur when normal persons assume an upright position (Staffor Harris and Weissler, 1970), brisk diuresis (Weisslet 1977; Buch et al., 1980), head-up tilt or application क्f venous occlusive tourniquets (Stafford et al., 1970 results in prolongation of PEP. Reduction in encे diastolic volume may be associated with a reduction in the force of $\mathrm{LV}$ contraction, while reduction in end-diastolic pressure (LVEDP) is associated with å 
TABLE 2. Factors affecting systolic time intervals

\begin{tabular}{|c|c|c|}
\hline Interval & Increase & Decrease \\
\hline PEP & $\begin{array}{l}\text { - preload and SV } \\
+ \text { afterload, } \\
\text { negative inotropic agents, } \\
\text { impaired myocardial contractility }\end{array}$ & $\begin{array}{l}\text { + preload and SV } \\
\text { - afterload, } \\
\text { positive inotropic agents, } \\
\text { enhanced myocardial contractility }\end{array}$ \\
\hline LVET & $\begin{array}{l}\text { + preload and SV, } \\
\text { + afterload, } \\
\text { - afterload }\end{array}$ & $\begin{array}{l}\text { - preload and SV, } \\
\text { positive and negative inotropic agents }\end{array}$ \\
\hline PEP/LVET & $\begin{array}{l}\text { - preload, } \\
\text { left ventricular diseases, } \\
\text { negative inotropic agents, }\end{array}$ & $\begin{array}{l}\text { + preload, } \\
\text { - afterload, } \\
\text { positive inotropic agents, }\end{array}$ \\
\hline QS2 & negative inotropic agents & positive inotropic agents \\
\hline
\end{tabular}

Abbreviations: - reduction; + increase; SV stroke volume.

increase pressure gradient across the aortic valve. These factors lead to prolongation in PEP. On the other hand, increase in stroke volume due to enhanced ventricular filling is accompanied by an abbreviation in PEP (Greenfield et al., 1968; Harley et al., 1969; Weissler et al., 1969). Changes in afterload are also important as aortic diastolic pressure determines aortic valve opening. Deviations in LVEDP may occur during pharmacological interventions. Reduction in peripheral resistance (Harris et al., 1967; Sawayama et al., 1969) results in shortening of PEP, while increase in peripheral resistance by angiotensin (Harris et al., 1967) and methoxamine (Shaver et al., 1968) prolongs PEP. PEP also depends on the myocardial contractility and inotropic state, so it is prolonged in heart failure (Weissler et al., 1968) and myxoedema (Crowley et al., 1977). Conversely, when LV contractility is increased as in thyrotoxicosis, PEP is short (Lien and Aandervd, 1982). PEP is shortened by positive inotropic agents and prolonged by negative inotropic agents (Harris et al., 1967; Lewis et al., 1976). Changes in the duration of the QRS complex and in the electromechanical interval will alter PEP, producing changes that have no haemodynamic significance (Metzger et al., 1970).

\section{LVET}

This is related inversely to heart rate (Harris et al., 1967; Weissler et al., 1968). It reflects the duration that the aortic valve remains opened, thus it is directly related to stroke volume (SV) (Weissler, Harris and White, 1963; Weissler et al., 1969; Harley et al., 1969). LVET is reduced by decreased SV relative to end-diastolic volume as in heart failure and decreased preload (Lewis et al., 1976), while enhanced left ventricular filling leads to prolongation of LVET. Both positive and negative inotropic agents cause a reduction in LVET (Lewis et al., 1976), while reduction and increase in afterload lead to prolongation of LVET. During methoxamine infusion, when SV, heart rate and inotropic state were held constant, LVET increased as mean arterial pressure increased (Shaver et al., 1968). Decrease in afterload prolongs LVET (Sawayama et al., 1969) due to the augmented stroke volume.

\section{PEP/LVET ratio}

This is relatively insensitive to changes in heart rate (Weissler et al., 1968), although atrial pacing was found to increase it (Johnson et al., 1981). It is increased with reduction in preload, negative inotropic agents and LV diseases (Weissler, 1977). Enhanced LV filling, positive inotropic agents and reduction in afterload lead to shortening of this ratio.

\section{QS2}

This is inversely related to heart rate and has been found to be variably affected by acute changes in SV brought about by changes in preload (Martin et al., 1971). These findings support those of Harley et al., (1969) who found the total duration of systole to increase when SV was augmented by an appropriate $\mathbf{P}-\mathbf{R}$ interval during atrial pacing studies in patients with complete heart block. QS2 best reflects the presence of positive inotropic stimulation, since both PEP and LVET are shortened (Lewis et al., 1976). A hallmark of the effect of positive inotropic agents is an abbreviation in QS2 and PEP (Weissler, 1977). A reduction in LVET usually, but not always, occurs, since associated haemodynamic changes such as an increase in stroke volume may have an opposite effect.

Use of systolic time intervals in clinical pharmacology

With the continuous flow of drugs into clinical 
pharmacology, knowledge of their cardiovascular effects becomes mandatory. Here the contribution of STI as an investigative tool has become apparent. It is a non-invasive test which can be performed repeatedly and gives quantitative data about LV performance. It can reveal many important pharmacodynamic properties of the tested drug which may be of great therapeutic relevance, such as time of onset, duration of action, effect on chamber dynamics and the presence of possible chronotropic and ionotropic actions. In the intact man, unlike the isolated heart, complex regulatory and intrinsic mechanisms act upon the heart and circulation. In pharmacological studies, where the drug can produce several haemodynamic influences, the study of the independent changes in heart rate, preload, afterload and myocardial contractility produced by the drug are often difficult. Because of these considerations, the STI should be viewed as a measure of chamber performance which, under the most rigorous condition, could be applied as a measure of contractility (Weissler et al., 1980). The data provided by the STI when combined with other tests of ventricular function can yield a more comprehensive, and hence more valid analysis of ventricular performance.

The main clinical application of STI measurements today is in the study of the effects of drugs on the cardiovascular system (Table 3). Many drugs have been studied since the 1960's. Digitalis glycosides have been studied extensively in normal subjects and patients (Weissler et al., 1964, 1965, 1970; Forester et al., 1974; Burgess, Turner and Wadsworth, 1978; Matos, 1980). There was general agreement that they produce an abbreviation in QS2I, PEP and heart rate. The effect on LVET was more controversial, some investigators found consistent dose-dependent reductions (Weissler et al., 1964), while others found no significant change. A temporal dissociation between chronotropic and inotropic actions of medigoxin was found in normal subjects (Burgess et al., 1978).

Isoprenaline infusion into normal subjects produced positive chronotropic and inotropic actions with a dose-related abbreviation in PEP (Harris et al., 1967). This reduction was due to the positive inotropic action of the drug and to the peripheral vasodilatation it produces. There was a concomitant shortening in LVET. Adrenaline and moderate doses of noradrenaline have similar actions (Harris et al., 1967). Pharmacological vasoconstriction, both alphaadrenergic (adrenaline and noradrenaline after propranolol) and by angiotensin, prolongs PEP (Harris et al., 1967) and LVET. Atropine, $2 \mathrm{mg}$ intravenously, abolished the vasoconstrictive-induced prolongation of PEP, although it augmented the pressor effect of noradrenaline and angiotensin. Atropine did not alter the PEP in normal subjects, nor did it inhibit the prolongation due to other causes such as head- $-\mathrm{mp}$ tilt or the closing of systemic arterio-venous fistulat. Pharmacological vasoconstriction, therefore, appea্⿸s to prolong PEP through reflex stimulation of the vagal efferent to the heart.

The effect of beta-adrenoceptor blockers on the duration of PEP varies with the specific agent used (Hunt et al., 1970). The degree of change in PEP affer intravenous propranolol was inversely proportion⿳亠口冋口 to its duration at rest (Ibrahim et al., 1974). Individ als with increased sympathetic activity, includiogg those with emotional tension and patients with phaeochromocytoma, show excessive lengthening $\overrightarrow{\text { of }}$ PEP in response to i.v. propranolol in comparison to a slight prolongation in normal subjects (Harris et \&D, 1967). Propranolol produces a negative inotropic effect as indicated by prolonged PEP and PE$P / L V E T$ ratio, and a negative chronotropic effect in normal subjects and in patients with various cardievascular diseases (Harris et al., 1967; Hunt et ab, 1970; Ibrahim et al., 1974; Frishman et al., 1975; van Herick and Aronow, 1978), with no significant effeegt on LVETI. A negative inotropic action was found after oral oxprenolol in normal subjects (Frei, Imhö and Dubach, 1974) and in patients with coronary artery disease (Van Herick et al., 1978). This wats manifested as a significant prolongation of PEP and PEP/LVET ratio without an effect on LVETI QS2I. Resting heart rate showed only a slight chinge (Van Herick and Aronow, 1978). Pindolol give 1 i to normal subjects produced no significant effe on any of the STI, which is probably because of ts

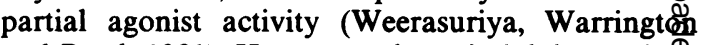
and Patel, 1981). However, when pindolol was given orally to patients with essential hypertension, \# produced directionally opposite changes in STI. En

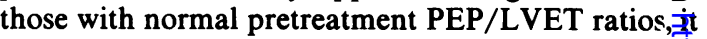
produced a significant increase in PEP and PE$P / L V E T$ ratio, and a significant decrease in LVET⿱8 while those with abnormally high PEP/LVET ratiogs showed the opposite changes, i.e., a reduction in PEP and PEP/LVET ratio and a prolongation of LVETI (Plotnick et al., 1980). This suggests that it hås different mechanisms for changing cardiac function in the 2 groups.

Beta-blockade effect predominates in the first group while the intrinsic sympathomimetic effect pindolol counteracts the beta-blocking effect in the second group. In both situations, no significafit change in heart rate was found.

In normal subjects, amyl nitrate inhalation pr民్ duced a significant prolongation in LVETI and a significant reduction in PEPI, while patients with ischaemic heart disease exhibited no significa changes, probably due to lack of increase in strol? volume and/or in contractility of the ischaemio myocardium (Sawayama et al., 1969). Glycer 
TABL: 3. Effects of some drugs on systolic time intervals

\begin{tabular}{lll}
\hline Drug & Significant STI changes & Possible mechanisms \\
\hline Digitalis glycosides & - PEP and QS2I & positive inotropic effect \\
Catecholamines & - PEP and QS2I & positive inotropic effect \\
Propranolol & + PEP and PEP/LVET & negative inotropic effect \\
Oxprenolol & + PEP and PEP/LVET & negative inotropic effect \\
Pindolol & none in normal subjects & partial agonist \\
(a) hypertensives with high PEP/LVET. & - PEP and PEP/LVET & partial agonist \\
& + LVETI & \\
(b) hypertensives with normal PEP/LVET & + PEP and PEP/LVET & negative inotropic effect \\
& - LVETI & \\
GTN & - QS2I and LVETI & reflex inotropic \\
Amyl nitrate & - PEP & afterload reduction \\
Hydralazine & + LVETI & \\
Calcium gluconate & - PEP & positive inotropic effect \\
Prostacyclin & - QS2I and LVETI & positive inotropic effect \\
PGF2-alpha & - PEP and QS2I & $\begin{array}{l}\text { reflex inotropic } \\
\text { increased SV }\end{array}$ \\
\hline & + LVETI & positive inotropic effect \\
\hline
\end{tabular}

Abbreviations: - decrease; + increase.

trinitrate (GTN), when given sublingually to normal subjects, produced an increase in heart rate, a decrease in QS2I and LVETI and little alteration in PEP and PEP/LVET ratio (Warrington and Burgess, 1980). These results are compatible with a vasodilator action of GTN, predominantly on the venous circulation with consequent mild tachycardia and inotropic stimulation. Oral hydralazine elicits a positive inotropic action in patients with left ventricular failure, shown as a significant shortening of PEP and an increase in the mean rate of rise of isovolumic pressure (Leier et al., 1980). The effect of prazosin on these inotropic variables was negligible. Amitriptyline increased the PEPI and PEP/LVET ratio, while mianserin has no effect on STI (Burgess et al., 1978). The finding with amitriptyline may indicate a decrease in myocardial contractility. The effect of acute changes in serum calcium upon STI may reflect an inotropic action of this ion on the human heart (Shiner et al., 1969), as infusion of $10 \%$ calcium gluconate consistently shortened QS2 and LVET and slowed heart rate.

The effect of various prostaglandins on STI have also been studied. Prostacyclin infusion produced a dose-related decrease in diastolic blood pressure, PEP and QS2I (Warrington, Smith and O'Grady, 1980 ) and an increase in LVETI (Hassan et al., 1982).
Pretreatment of the subjects with atenolol or propranolol did not modify these STI findings. Infusion of prostaglandin F2 alpha (PGF2 alpha) in 5 healthy pregnant women during abortion produced a significant rise in cardiac output, arterial blood pressure and a significant reduction in PEP and PEP/LVET ratio. This suggests that it may have a positive inotropic action, as rising cardiac output and blood pressure should increase the PEP (Thayssen, Secher and Arnsbo, 1981). On the other hand, PGE2 infused into another 5 women under the same conditions produced a significant fall in PEP and PEP/LVET ratio consequent to the fall in peripheral resistance which occured (Thayssen et al., 1981). No significant rise in LVETI was seen in either situation.

Another application for the use of STI is in patients receiving adriamycin for treatment of malignant diseases; here, monitoring of PEP/LVET ratio may detect early cardiotoxicity and prevent lifethreatening heart failure (Rinehart, Lewis and Bolcerzak 1974; Al-Ismail and Whittaker, 1979).

\section{The study of systolic time intervals in diseases}

The application of STI in clinical practice is based on the fact that they are well regulated under normal circumstances so that they fall within narrow physio- 
TABLE 4. Effects of some diseases on systolic time intervals

\begin{tabular}{ll}
\hline Disease & Possible Systolic Time Interval Changes \\
\hline Chronic myocardial dysfunction & long PEP, short LVETI, high PEP/LVET and normal QS2I \\
Acute myocardial infarction & early: short PEP, LVETI and QS2I, late: long PEP and short LVETI \\
Aortic stenosis & short PEP, long LVETI, low PEP/LVET and long QS2I \\
Aortic regurgitation & short PEP, long LVETI and low PEP/LVET \\
Mitral stenosis & short LVETI \\
Mitral regurgitation & usually normal STI \\
Left bundle branch block & long PEP and high PEP/LVET \\
Hypothyroidism & long PEP, short LVETI and high PEP/LVET \\
Hyperthyroidism & short PEP, long LVETI and low PEP/LVET \\
Diabetes mellitus & long PEP, short LVETI and high PEP/LVET \\
Chronic alcoholism & long PEP, short LVETI and high PEP/LVET \\
\hline
\end{tabular}

logical limits (Weissler, 1977), and that alterations in STI reflect not only transient haemodynamic changes but also accompany sustained alterations in LV performance. It is on these facts that the interest in the study of STI changes in various cardiovascular diseases (Table 4) is based (Weissler et al., 1972). In chronic myocardial diseases (Weissler et al., 1968; 1969), the typical STI pattern of left ventricular dysfunction is prolongation of PEP, shortening of LVETI, and normal QS2I. Among patients with reduced cardiac output (CO), the magnitude of deviation in PEPI and LVETI correlates closely and significantly with stroke volume (SV) and cardiac output (Weissler et al., 1972), the more severe the disease, the more marked the deviations. Furthermore, among patients in whom $\mathrm{CO}$ and SV fell within normal limits, significant deviations in PEPI and LVETI were still frequent. Thus, while the changes in STI might accompany alteration in SV and $\mathrm{CO}$, they probably were not causally related to these haemodynamic events. Rather it appeared that the changes in STI were the direct result of overall changes in LV performance (Weissler et al., 1972). A good correlation between PEP/LVET ratio and stroke index was found among patients with arteriosclerotic, hypertensive, and primary myocardial diseases (Weissler et al., 1969). The PEP/LVET ratio was found to be a more sensitive index of left ventricular dysfunction than is the cardiac index or stroke index (Lewis et al., 1970). Increased PEP/ LVET ratio to 0.44 or greater may denote the presence of diminished LV performance, mild $(0.44-0.52)$, moderate $(0.53-0.60)$ and severe more than 0.60 (Weissler, 1977). Patients with hypertension and minimal functional impairment may show no abnormalities in STI (Weissler et al., 1969; Ibrahimgt al., 1974; Plotnick et al., 1980). In the course of acute myocardial infarction (AMI), an early observation was shortened QS2I in nearly all patients (Toutouzâs et al., 1969). Subsequently, this was found to be dye to high adrenergic tone in AMI (Lewis et al., 189 and a strong correlation was found between uritary adrenaline and noradrenaline excretion and This shortening of QS2I can be reversed towaress normal by administration of IV propranolol (Lewis al., 1976). The high adrenergic tone will profound affect the usual pattern of prolongation of PEP a Pd shortening seen in the presence of myocardial d $\overrightarrow{\mathrm{E}}-$ function (Lewis et al., 1976). Thus, a normal PE五I and PEP/LVET ratio in AMI with the high level $\overline{8 f}$ adrenergic tone actually represents $L V$ dysfunction (Lewis et al., 1977). Among patients who convalescee after previous AMI, the STI may reveal the presence of residual abnormalities, e.g. an increase in PEश and PEP/LVET ratio when clinical and radiologicgl evidence for such cardiac abnormality is abseat (Weissler et al., 1980). Favourable survival rate among patients with a previous $\mathrm{MI}$ is when their PEP/LVET ratio is normal even in the presence of two or three vessel disease, while those with abnor. mal ratio have diminished survival (Weissler et do 1981). In coronary artery disease, the PEP/LVET ratio was found to correlate with the angiograplim cally determined left ventricular ejection fraction (Lewis et al., 1976) and to have a significa prognostic value (Gillilan et al., 1979). On life-tabibe analysis, the difference between subjects with resting PEP/LVET ratio more than 0.50 and those with:a ratio less than 0.50 was highly significant. The ratip was more predictive of mortality than other par? 
TABLE 5. Non-invasive techniques to study cardiac function and performance

\begin{tabular}{|c|c|c|c|c|}
\hline Method & Cost & $\begin{array}{l}\text { Convenience } \\
\text { to patients }\end{array}$ & $\begin{array}{l}\text { Ease of } \\
\text { learning }\end{array}$ & $\begin{array}{l}\text { Application to } \\
\text { all subjects }\end{array}$ \\
\hline Systolic time intervals & cheap & convenient & easy & almost all \\
\hline Apex cardiography & cheap & convenient & easy & almost all \\
\hline $\begin{array}{l}\text { Ultrasound study } \\
\text { M-mode echo } \\
\text { Two-dimensional }\end{array}$ & $\begin{array}{l}\text { expensive } \\
\text { expensive }\end{array}$ & $\begin{array}{l}\text { convenient } \\
\text { convenient }\end{array}$ & $\begin{array}{l}\text { difficult } \\
\text { difficult }\end{array}$ & $\begin{array}{l}\text { not all } \\
\text { not all }\end{array}$ \\
\hline Radionuclide imaging techniques & expensive & $\begin{array}{l}\text { less } \\
\text { convenient }\end{array}$ & difficult & not all \\
\hline Impedance plethysmography & expensive & convenient & difficult & almost all \\
\hline Cardiac output measurement using indocyanine green dye solution & cheap & convenient & easy & almost all \\
\hline
\end{tabular}

meters including resting ECG, maximum tolerance testing data and cardiac catheterization. However, others (Parker and Just, 1974) doubted the value of STI in the clinical assessment of coronary artery disease. They found no group deviation from normal and no significant correlation between either STI absolute values or their changes with $\mathrm{dp} / \mathrm{dt} \max$, ejection fraction, or asynergy was found. In anaemia, uraemia, nephrotic syndrome and liver cirrhosis where fluid overload may cause pulmonary oedema, STI are usually normal, if no underlying heart disease is present (Lewis, 1975). Prolongation of PEPI and PEP/LVET ratio with shortening of LVETI indicating cardiac depression may be found in diabetes mellitus (Ahmed et al., 1975), hypothyroidism (Crowley et al., 1977) and in chronic alcoholism (Spodick et al., 1972). In diabetes mellitus, the STI changes were independent of duration and mode of therapy of the disease.

\section{Systolic time intervals and decision making}

A recently applied clinical use of STI is in the study of the cardiovascular system before, during and after operations (Dauchat and Gravenstein, 1980). Pre-operatively, the STI can offer information regarding cardiac performance, although normal STI do not exclude the presence of heart disease. Intraoperatively, automated STI monitoring provide continuous data acquisition and instantaneous delivery of information about haemodynamic changes, effects of drugs and anaesthetics used on the cardiovascular system, and responses to treatment (calcium, fluid replacement, afterload reduction). Postoperatively, STI may be helpful prognostically and in assessment of the results of medical and surgical treatment as in coronary artery disease (Lewis et al., 1976).
Place of systolic time intervals among other noninvasive techniques

Several non-invasive techniques (Table 5) have been developed to assess myocardial function and performance, and it is necessary to put systolic time intervals in perspective among them. In evaluating their use in clinical practice, several considerations must be remembered (Shine et al., 1980):

(1) Can the procedure produce results that will spare the patient additional investigations of greater risk, discomfort or cost?

(2) Does the procedure represent a new quantitative standard for diagnosis or treatment that may potentially replace currently available procedures at a lower morbidity or cost?

(3) Will the procedure permit repetitive evaluation of a patient for study of the natural history of disease, response to therapy or the outcome of interventions?

The three principal methods in use at present include systolic time intervals, $\mathbf{M}$-mode and crosssectional echocardiography and radionuclide angiography (Braunwald, 1980). Some of these procedures need increasingly sophisticated and expensive equipment ranging from the electronic scanners for echocardiographic use to radionuclide techniques requiring a cyclotron (Shine et al., 1980). Echocardiography and radionuclide angiography provide alternative methods to contrast angiography for measurements of ventricular volume and/or dimensions, and allow the non-invasive estimation of ejection phase indices (Braunwald, 1980). Echocardiography is an accepted non-invasive tool for the assessment of cardiac anatomy and function. Nevertheless, it has important limitations including high cost, the need to understand unfamiliar tomographic anatomy, a variable image presentation making standardization difficult and a need for greater physician-technician 
interaction for the best results (Seward and Tajik, 1980). The M-mode echo assesses only a small portion of the ventricular myocardium and does not always represent the overall left ventricular performance. Despite improvements in echo techniques and instrumentation, there are still many patients in whom it is difficult to record satisfactory echocardiograms and this represents a significant limitation of its use (Feigenbaum, 1980). Whether the heart is examined with an $\mathrm{M}$-mode or cross-sectional device, proper angulation of the ultrasonic beam is critical. Echo controls can also influence the image profoundly and the operator must be skilled to ensure that artifacts and distortion are not introduced through improper use of the gain control. Thus, although the echo examination is simple and painless for the patient, it can be extremely difficult to perform, so that a well trained individual is required for both the examination and the interpretation of results (Feigenbaum, 1980). Radionuclide imaging of the heart and cardiovascular system have important implications for the functional evaluation of patients with cardiac disorders, especially those with coronary artery disease (Maisey, Hilson and Wainwright, 1982). The two techniques which have the widest application at present are rest-and-stress thalliumimaging of the myocardium, and radionuclide ventriculography (Maisey, et al., 1982). However, the use of radionuclide imaging of the heart to study drug effects is limited.

In clinico-pharmacological assessment of myocardial performance, measurement of systolic time intervals has some favourable advantages over other non-invasive techniques. It is a quantitative measurement that requires relatively cheap equipment and can be carried out in almost all subjects without discomfort. The technique can be easily learnt, and within- and between-observer accuracy is good (Burgess et al., 1979). However, in the assessment of positive inotropic effect of drugs, STI and M-mode echo are complementary and both are less sensitive than $\mathrm{dp} / \mathrm{dt}$ max measured during cardiac catheterization (Walsh, Crawford and O'Rourke, 1982).

\section{Conclusions}

The STI is a helpful, non-invasive method to study left ventricular performance in health and disease. One must remember that it is virtually impossible to interpret STI findings without knowledge of the clinical setting in which the measurements are made and the physiological and pharmacological influences which affect performance of the heart (Weissler, 1980). The complex regulatory and intrinsic mechanisms controlling the heart and circulation in intact subjects make it difficult to draw definitive final conclusions from STI especially in pharmacological studies. Tests of ventricular contractility are, therefore, best confined to controlled studies $\frac{0}{8 n}$ single ventricle or isolated cardiac muscle prepa fations. The STI, finally, should be viewed as $\frac{\widehat{\alpha}}{a}$ measure of chamber performance which is rot competitive with other invasive or non-invasive tests of cardiac function, but is particularly well suited clinical pharmacological studies.

\section{References}

Ahmed, S., Levinson, G.E., Schwartz, C.J. \& Ettinger, P(D). (1972) Systolic time intervals as a measure of the contractile sate of the left ventricular myocardium in man. Circulation, 46, 291

AL-ISMAIL, S.A.D. \& WhitTAKER, J.A. (1979) Systolic time interal as an index of schedule-dependent doxorubicin cardiotoxicityin patients with acute myelogenous leukaemia. British Medigal Journal, 1, 1392.

BRAUNWALD, E. (1980) Assessment of cardiac performance. $\bar{g}_{n}$ : Heart Disease (Ed. E. Braunwald) (W.B. Saunders Company. Philadelphia, London, Toronto.

Buch, J., Egebland, H., Hansen, P.B., KJaegard, H., w\&্ֶু. DORFF, S. \& STEIEN, E. (1980) Correlation between change\&in systolic time intervals and left ventricular end-diastolic diamsfer after preload reduction; non-invasive monitoring of pharmacological intervention. British Heart Journal, 44, 668.

BurG, J.I., DodeK, L. \& Kloster, F.E. (1972) Systolic tiffie intervals in pregnancy. Clinical Research, 30, 365 .

Burgess, C.D. (1981) M.D. Thesis, University of Cape Town "The investigation of the cardiovascular effects of antidepressant drugs using non-invasive techniques."

Burgess, C.D., Turner, P. \& Wadsworth, J. (1978) Cardiovâscular responses to mianserin hydrochloride: a comparisoz tricyclic antidepressant drugs. British Journal of Clinical Pharma. cology, 5, $21 \mathrm{~s}$.

Burgess, C.D., WADSWORTH, J. \& WARRINGTON, S.J. \&98) Evaluation of some non-invasive indices of cardiovascula furction. British Journal of Clinical Pharmacology, 7, 436p.

Bush, C.A., Lewis, R.P., Leighton, R.F., Fontana, M.E. $\bar{g}$ WEISSLER, A.M. (1970) Verifaction of systolic time intervals and the true isovolumic contraction time from the apexcardiogramsy micromanometer catheterization of the left ventricle and aorta. Circulation, 41, 42 (Suppl III), III-121.

CANTOR, A., WANDERMAN, K.L., KaROLEVITCH, T., OVSYSHCHER, I. \& Gueron, M. (1978) Systolic time intervals in childrep: normal standards for clinical use. Circulation, 58, 1123.

Crowley, JR. W.F., Ridgway, E.C., Bough, E.W., Francis, G.S., Daniels, G.H., Kourides, I.A., MYers, G.S. \& Maloof, $\bar{q}$. (1977) Non-invasive evaluation of cardiac function in hypotyroidism response to gradual thyroxine replacement. New Englisind Journal of Medicine, 296, 1.

Dauchat, P.J. \& Gravenstein, J.S. (1980) Use of systolic time intervals in the operating room. In: Systolic time intervals (Ed W. List, J.S. Gravenstein and D.H. Spodick). Springer-Verlag, Berfin Heidelberg, New York.

FelgenbaUM, H. (1980) Echocardiography. In: Heart Disease (Ed. E. Braunwald) W.B. Saunders Company, Philadelphia, London, Toronto.

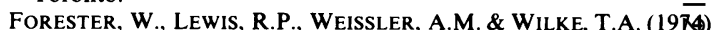
The onset and magnitude of the contractile response to commonly used digitalis in normal subjects. Circulation, 44, 517.

FreI, F., IMHOF, P. \& DUBACH, U.C. (1974) Effects of alpha- atit beta-receptor blockade on systolic time intervals. Europ\&en Journal of Clinical Pharmacology, 7, 1.

Frishman, W., Smithen, C., Befler, B., Kligfield, P. \& Kilip (1975) Non-invasive assessment of clinical response to cral propranolol therapy. American Journal of Cardiology, 35, 635

Garrard, JR. C.L., Weissler, A.M. \& Dodge, H.T. (1970) THe relationship of alteration in systolic time intervals to ejection fraction in patients with cardiac disease. Circulation, 42, 455. 
Gillil.an, R.E., Parnits, W.P., KHan, M.A., Bou(hari), R.J. \& Warbasst:, J.R. (1979) The prognostic value of systolic time intervals in angina pectoris patients. Circulation. 60, 268.

GOLDE, D. \& BURSTIN, L. (1970) Systolic phases of the cardiac cycle in children. Circulation, 42, 1029.

Greenfield, J.C. JR., Harley, A., Thompson, H.K. \& Wall.ac'., A.G. (1968) Pressure-flow studies in man during atrial fibrillation. Journal of Clinical Investigation, 47, 2411.

Harley, A., Starmer, C.F. \& Greenfield, J.C. JR. (1969) Pressure-flow studies in man. An evaluation of the duration of the phases of systole. Journal of Clinical Investigation, 48, 895.

HARRIS, W.S., SCHOENFELD, C.D. \& WeIsSLER, A.M. (1967) Effects of adrenergic receptors activation and blockade on the systolic preejection period, heart rate and arterial pressure in man. Journal of Clinical Investigation, 46, 1704.

harrison, T.R., Dixon, K., Russell, JR. R.O., Bidwai, P.S. \& Coleman, H.N. (1964) Relation of age to the duration of contraction, ejection and relaxation of the normal human heart. American Heart Journal, 67, 189.

Hassan, S., Pickles, H., Fish, A., Burke, C., Warrington, S. \& O'GRADY, J. (1982) The cardiovascular and platelet effect of epoprostenol (prostacyclin, PGI2) are unaffected by beta-adrenoceptor blockade in man. British Journal of Clinical Pharmacology, $14,369$.

Hunt, D., Sloman, G., Clark, R.M. \& Hoffman, G. (1970) The effects of beta-adrenergic blockade on the systolic time intervals. American Journal of Medical Sciences, 259, 97.

Ibrahim, M.M., TARAZI, R.C., DUSTAN, H.P. \& Bravo, E.L. (1974) Cardioadrenergic factor in essential hypertension. American Heart Journal, 88, 724.

Johnson, B.F., Meeran, M.K., Frank, A. \& TaYlor, S.H. (1981) Systolic time intervals in measurement of inotropic response to drugs. British Heart Journal, 46, 513.

Kelman, A.W., Sumner, D.J. \& Whiting, B. (1981a) Systolic time intervals $v$ heart rate regression equations using atropine: reproducibility studies. British Journal of Clinical Pharmacology, 12, 15.

Kelman, A.W. \& Sumner, D.J. \& Whiting, B. (1981b) The prediction of individual systolic time interval $v$ heart rate regression equations. British Journal of Clinical Pharmacology, 12, 21.

Kher, H.L., Grover, D.N. \& DuRaIRAJ, M. (1980) Left ventricular function during pregnancy by non-invasive technique. Indian Journal of Medical Research, 72, 512.

Leier, C.L., Desch, C.E., Magorien, R.D., Tiffon, D.W., UNVERFERTH, D.V., Boudoulas, H. \& LEWIS, R.P. (1980) Positive inotropic effect of hydralazine in human subjects: comparison with prazosin in the setting of congestive heart failure. American Journal of Cardiology, 46, 1039.

LEWIS, R.P. (1975) Diagnostic value of systolic time intervals in man. In: Diagnostic Methods in Cardiology (Ed. N.O. Fowler). Davis, F.A., Philadelphia.

LeWIS, R.P., Boudoulas, H., Forester, W.F. \& Weissler, A.M. (1972) Shortening of electromechanical systole as a manifestation of excessive adrenergic stimulation in acute myocardial infarction. Circulation, 46, 856

LEwIS, R.P., Boudoulas, H., Ruff, P. \& Kates, R.E. (1980) Systolic time intervals for the diagnosis and management of coronary artery disease. In: Systolic time intervals (Eds. W.F. List, J.S. Gravenstein, and D.H. Spodick). Springer-veralg, Berlin, Heidelberg, New York.

LEWIS, R.P., Boudoulas, H., Welch, T.G. \& Forester, W.F. (1976) Usefulness of systolic time intervals in coronary artery disease. American Journal of Cardiology, 37, 787.

Lewis, R.P., RitTGers, S.E., Forester, W.F. \& Boudoulas, H. (1977) A critical review of the systolic time intervals. Circulation, $56,146$.

LeWIS, R.P., Marcus, D.R., Garrard, C.L. \& Weissler, A.M. (1970) Abnormal systolic time intervals with normal cardiac output in chronic myocardial disease. Circulation, 41, 42 (suppl III), IIJ-65.
LitN, E. \& AANIDERVI), S. (1982) Systolic time intervals in the evaluation of thyroid dysfunction. Acta medica Scandinavica, 211, 265.

Maisey, M., HII.SON, A.J.W. \& Wainwrigitt, R. (1982) Radionuclide studies in the investigation of the cardiovascular system. Medicine International, 1, 779 .

Martin, C.E., Shaver, J.A., Thompson, M.E., Reddy, P.S. \& LEONARD, J.J. (1971) Direct correlation of external systolic time intervals with internal indices of left ventricular function in man. Circulation, 44, 419.

Matos, L. (1980) Systolic time interval measurements for the assessment of the effect of cardiovascular drugs. In: Systolic time intervals (Eds. W.F. List, J.S. Gravenstein and D.H. Spodick). Springer-Verlag, Berlin, Heidelberg, New York.

Metzger, C.C., Chough, C.B., Kroetz, F.W. \& Leonard, J.J. (1970) true isovolumic contraction time its correlation with two external indices of ventricular performance. American Journal of Cardiology, 25, 434.

Parker, M.E. \& JUST, H.G. (1974) Systolic time intervals in coronary heart disease as indices of left ventricular function: Fact or Fancy. British Heart Journal, 36, 368.

Plotnick, G.D., Fisher, M.L., Hamilton, J.H., Robinson, M., Carliner, N.H., Janowski, A.H. \& Hamilton, B.P. (1980) Pindolol in the treatment of hypertension: systolictime intervals as a predictor of response to beta receptor blockade. American Journal of Cardiology, 45, 614.

RINEHART, J.T., LEWIS, R.P. \& BolCERZAK, S.P. (1974) Adriamycin cardiotoxicity in man. Annals of Internal Medicine, 81, 475.

RoBINSON, B. (1963) The carotid pulse II: Relation of external recordings to carotid, aortic, and brachial pulses. British Heart Journal, 25, 61.

Rubler, S., SChneebaum, R. \& Hammer, N. (1973) Systolic time intervals in pregnancy and the postpartum period. American Heart Journal, 86, 182.

Sawayama, T., Ochial, M., Marumato, S., Mastuura, T. \& NIK I, I. (1969) Influence of amyl nitrate inhalation on the systolic time intervals in normal subjects and in patients with ischemic heart disease. Circulation, 40, 327.

SEWARD, J.B. \& TAJIK, A.J. (1980) Two-dimensional echocardiography. Medical Clinics of North America, 64, 177

Shaver, J.A., Kroetz, F.W., Leonard, J.J. \& Paley, H.W. (1968) The effect of steady-state increases in systolic arterial pressure on the duration of left ventricular ejection time. Journal of Clinical Investigations, 47, 217.

Shine, K.I., Perloff, J.K., Child, J.S., Marshall, R.C. \& SCHELBERT, N. (1980) Noninvasive assessment of myocardial function. Annals of Internal Medicine, 92, 78.

Shiner, P.T., HaRRIS, W.S. \& WeisSler, A.M. (1969) Effects of acute changes in serum calcium levels on the systolic time intervals in man. American Journal of Cardiology, 24, 42.

Slodki, S.J., Hussain, A.T. \& LuISAda, A.A. (1969) The Q-Il interval; III Study of the second heart sound in old age. Journal of the American Geriatrics Society, 17, 673 .

SPODICK, D.H. (1977) Measurement of cardiac pre-ejection period. New England Journal Medicine, 296, 822.

SPODICK, D.H., Ball, H.G. \& PigotT, V.M. (1978) Effect of recording speed on precision of time-based polycardiographic measurements optimal paper speed for measuring points and intervals. British Heart Journal, 40, 1344.

Spodick, D.H., PIgotT, V.M. \& CHIRIFE, R. (1972) Preclinical cardiac malfunction in chronic alcoholism. New England Journal Medicine, 287, 677.

STACK, R.S., Sohn, Y.H. \& WeISSLER, A.M. (1981) Accuracy of the systolic time intervals in detecting abnormal left ventricular performance in coronary artery disease. American Journal of Cardiology, 47, 603

Stafford, R.W., Harris, W.S. \& Weissler, A.M. (1970) Left ventricular systolic time intervals as indices of postural circulatory stress in man, Circulation, 41, 485. 
Thayssen, P.. Secher, N.J. \& ARnsbo, P. (1981) Systolic time intervals and haemodynamic changes during intravenous infusion of prostaglandin F2 alpha and E2. British Heart Journal, 45, 447.

Tourouzas, P., GuPTA, D., Samson, R. \& Shilling, F.J. (1969) Qsecond sound interval in acute myocardial infarction. British Heart Journal, 31, 462.

VAN HERICK, R. \& ARONOW, W.S. (1978) Effects of oxprenolo and propranolol on systolic time intervals. Clinical Pharmacology and Therapeutics, 24, 678.

Walsh, R.A., Crawford, M.H. \& O'Rourke, R.A. (1982) Relative sensitivity of echocardiography and systolic time intervals for assessing acute positive interventions in normal human subjects. American Heart Journal, 104, 1061.

Wanderman, K.I., Hayek, Z., OVSyshcher, I., Loutaty, G., CANTOR, A., GUSSARSKY, Y., GUERON, M. \& DADON, B. (1981) Systolic time intervals in adolescents. Normal standards for clinical use and comparison with children and adults. Circulation. 63, 204.

WARRINGTON, S.J. \& BURGESS, C.D. (1980) Effect of glyceryl trinitrate on the systolic time intervals. British Journal of Clinical Pharmacology, 9, 292p.

Warrington, S.J., Smith.. P.R. \& O'Grady, J. (1980) Noninvasive assessment of the cardiovascular effects of prostacyclin (PGI2) in man. European Journal of Cardiology, 12, 73.

Weerasuriya, K., Warrington, S.J. \& Patel, L. (1981) Detection of partial agonist activity of pindolol using systolic time intervals. British Journal of Clinical Pharmacology, 13, 268p.

WeerasuriYa, K. (1982) Ph. D. Thesis submitted to the University of London.

WEISSLER, A.M. (1977) Systolic time intervals. New England Journal Medicine, 296, 321

Weissler, A.M., Gamel, W.G., Grade. H.E., Cohen, S. \& SCHOENFELD, C.D. (1964) Effect of digitalis on ventricular ejection in normal human subjects. Circulation, 29, 721.

WeISSlER, A.M., HARRIS, W.S. \& SCHOENFELD, C.D. (1968) Systolic time intervals in heart failure in man. Circulation, 37, 149.
Weissler, A.M., HARRIS, W.S. \& SChoenfeld, C.D. (196 Bedside technics for the evaluation of ventricular function in $\mathrm{m}$. American Journal of Cardiology, 23, 577.

WeIssler, A.M., HARRIS, L.C. \& White, G.D. (1963) Le ventricular ejection time index in man. Journal of Applied Physiology, 18, 919.

Weissler, A.M., KAmem, A.R., Bornstein, R.S., Shoenfel C.D. \& COHEN, S. (1965) Effect of deslanoside on the durations 8 f the phases of ventricular systole in man. American Journatef Cardiology, 15, 153.

WEISSLER, A.M., LEWIS, R.P. \& LEIGHTON, R.F. (1972) The systo time intervals as a measure of left ventricular performance in man In: Progress in cardiology, $1,155$.

WeISSLER, A.M., O'WeIll, W.W., SOHN, Y.H., STACK, R.S., CheW. P.C. \& REED, A.H. (1981) Prognostic significance of systolic tiffe intervals after recovery from myocardial infarction. Americ Journal of Cardiology, 48, 995.

Weissler, A.M., PeEler, R.G. \& ROEHLl, JR. W.H. (196+ Relationships between left ventricular ejection time, stro volume, and heart rate in normal individuals and patients with cardiovascular disease. American Heart Journal, 62, 367.

WeISSLER, A.M. \& SCHOENFELD, C.S. (1970) The effect of digitath on systolic time intervals in heart failure. American Journal of Medical Science, 259, 4.

WEISSLER, A.M., STACK, R.S. \& SoHN, Y.H. (1980) The accuracy of the systolic time intervals as a measure of left ventricular function? In: Systolic time intervals (Ed. W.F. List, J.S. Gravenstein a dि D.H. Spodick). Springer-Verlag, Berlin, Heidelberg, New YorkN Werf, F. van De. Piessens, J., Kesteloot, H. \& Geest, H. (1975) A comparison of systolic time intervals derived from the central aortic pressure and from the external carotid pulse tracing. Circulation, 51, 310.

Willems, J.L., Roelandt, T., De Gesst, H., Kesteloot, H. JOSSENS, J.V. (1970) The left ventricular ejection time in elde subjects. Circulation, 42, 37.

(Accepted 27 January 1983) 